\title{
EXPANSÃO DA CANA-DE-AÇÚCAR NA MICRORREGIÃO SUDOESTE DE GOIÁS: ANÁLISE ESPACIAL DAS MUDANÇAS DO USO E COBERTURA DO SOLO NOS ANOS DE 2001, 2006 E 2011
}

\author{
EXPANSION OF CANE SUGAR IN SOUTHWEST MICROREGION GOIÁS: \\ SPATIAL ANALYSIS OF THE LAND USE AND COVER CHANGE IN THE YEARS \\ 2001, 2006 AND 2011
}

\author{
EXPANSIÓN DE LA CAÑA DE AZÚCAR EN LA MICRORREGIÓN SUR-OESTE \\ DE GOIÁS: ANÁLISIS ESPACIAL DE LOS CAMBIOS DE LA CUBIERTA \\ VEGETAL Y USO DEL SUELO EN LOS AÑOS 2001, 2006 Y 2011
}

\author{
Íria Oliveira Franco - Raízen - Jataí - Goiás - Brasil \\ iria_biologa@ymail.com
}

\begin{abstract}
Resumo
0 interesse mundial em diminuir a dependência pelos combustíveis fósseis e diversificar a matriz energética para atenuar 0 aquecimento global tem despertado a atenção para os biocombustíveis, em especial o etanol de cana-de-açúcar, 0 que tem promovido a expansão das áreas de cultivo canavieiro e 0 aumento do número de usinas, notadamente em terras do Cerrado, sobretudo nos estados de Goiás e Mato Grosso do Sul. Para atender à demanda crescente de etanol é necessário aumentar a produção de cana-de-açúcar, mediante o incremento tanto da área cultivada quanto da produtividade. 0 sudoeste de Goiás (SW) é um espaço dominado pelo agronegócio, especialmente por atividades da cadeia carne-grãos, as quais, durante as últimas décadas, foram praticamente absolutas na definição da dinâmica espacial nessa região. 0 objetivo foi analisar a conversão do uso e ocupação do solo para cana-de-açúcar no SW de Goiás no período 2001-2006 e no ano de 2011. De toda área cultivada com cana na região no ano de $2011,55 \%$, 28\% e 17\% ocorreram em áreas onde, em 2006, eram agricultura, pastagem e cerrado, respectivamente. Desse modo, as áreas de agricultura representam mais da metade de todas as áreas substituídas por cana-de-açúcar no SW de Goiás no ano de 2011, comprovando a preferência por elas, em virtude das vantagens agronômicas, se comparadas às áreas de pastagem.
\end{abstract}

Palavras-chave: cana-de-açúcar, substituição de culturas, sensoriamento remoto, sudoeste de Goiás.

\section{Abstract}

The worldwide interest in reducing dependence on fossil fuels and diversify the energy matrix to mitigate global warming, has attracted attention to bio fuels, especially ethanol from sugar cane, which promoting strongly expansion of sugar cane cultivation area and increase of number of mills, concentrated on Cerrado region, particularly on Goiás and Mato Grosso do Sul states. To face the growing demand for ethanol it is necessary to increase the production of sugar cane as much as the increase of the cultivated area as well as increasing the productivity. The southwestern Goiás (SW) is dominated by agribusiness, especially for meat - grains chain activities which, during the last decades, were practically absolute in defining the spatial dynamics in this region. The objective was to analyze the conversion of the use and land occupation for sugar cane in the SW of Goiás, in the years 2001, 2006 and 2011. Of all the area cultivated with sugarcane in the region in $2011,55 \%$, $28 \%$ and $17 \%$ occurred in areas where, in 2006 , were occupied with agriculture activity, grassland and savanna, respectively. Thus, the areas of agriculture represent more than half of all the areas replaced by sugar cane SW of Goiás in 2011, showing a preference for agricultural areas, due to agronomic advantages compared to grazing areas.

Key words: sugar cane, crop substitution, remote sensing, southwest of Goiás. 
Íria Oliveira Franco

Resumen

El interés mundial en la reducción de la dependencia de los combustibles fósiles y diversificar la matriz energética para mitigar el calentamiento global, ha llamado la atención sobre los biocombustibles, especialmente el etanol de caña de azúcar, estimulando el crecimiento de las áreas de cultivo e de lo número de usinas. Para satisfacer la creciente demanda de etanol es necesario aumentar la producción de caña de azúcar tanto como el aumento de la productividad en el área cultivada. El sur-oeste de Goiás (SO) está dominado por la agroindustria, en especial para las actividades de la cadena de carne y de granos que, durante las últimas décadas, fue prácticamente absoluta en la definición de la dinámica espacial en esta región. El objetivo fue analizar la conversión del uso y la ocupación de tierras para la caña de azúcar en el S0 de Goiás, en los años 2001, 2006 y 2011. De toda área cultivada con caña de azúcar en región en $2011,55 \%$, $28 \%$ y $17 \%$ ocurrió en zonas donde, en 2006, estaban la agricultura, los pastizales y sabanas, respectivamente. De este modo, las áreas de la agricultura representan más de la mitad de todas las áreas reemplazados por caña de azúcar en el Sur-oeste (SO) de Goiás en 2011, mostrando una preferencia por las áreas de la agricultura, debido a las ventajas agronómicas en comparación con las zonas de pastoreo.

Palabras clave: caña de azúcar, la sustitución de cultivos, de teledetección, al sur-oeste de Goiás.

Introdução

A cana-de-açúcar é uma das culturas agrícolas de grande importância econômica no Brasil desde os tempos da Colônia, porém, teve maior destaque na década de 1970, quando o Programa do Álcool (Proálcool) elevou o país à posição de um dos maiores exportadores de açúcar e etanol, e colocou em evidência a região Sudeste, sobretudo o estado de São Paulo, como hegemônico na produção e exportação desses produtos até os dias atuais. Contudo, por causa do interesse recente do governo federal em diminuir a dependência pelos combustíveis fósseis e da preocupação global com o meio ambiente, o uso do etanol vem tornando-se uma alternativa energética de interesse mundial, induzindo à expansão do cultivo da cana-de-açúcar para a produção desse biocombustível.

Em 2003, com a inserção dos automóveis bicombustíveis no mercado consumidor brasileiro, ocorreu uma inusitada expansão de áreas cultivadas com cana-de-açúcar, que passaram de 5,4 milhões de hectares em 2003 para 9,2 milhões de hectares em 2010 (IBGE, 2012), ou seja, a área desse cultivar quase dobrou. Essa expansão pôde ser sentida nos principais estados produtores da cultura, entre eles, Goiás, que sofreu um aumento de 580 mil hectares na área cultivada com cana. No ano-safra 2011/2012, Goiás apresentou uma área cultivada com cana de 732 mil hectares, sendo o terceiro maior produtor de cana do Brasil, atrás apenas de São Paulo, com 5,4 milhões de hectares, e Minas Gerais, com 828 mil hectares. Entre as microrregiões do estado de Goiás, a sudoeste vem destacando-se pelo número de usinas instaladas e pelos impactos diretos da 
rápida expansão da cultura da cana em áreas estabelecidas anteriormente com a produção de grãos, especialmente a soja.

O monitoramento e o gerenciamento de toda a cadeia produtiva da cana-de-açúcar, a iniciar pelo seu cultivo, é imprescindível para o estabelecimento de políticas públicas de segurança alimentar e zoneamento agrícola, bem como de estratégias de mercado. Para tal, imagens obtidas por satélites de sensoriamento remoto são relevantes ferramentas para a obtenção de dados, tais como área cultivada, novas áreas de plantio, colheita, principalmente porque a cana-de-açúcar é uma monocultura semiperene e plantada em grandes áreas (Rudorff et al., 2004, 2005).

O objetivo deste trabalho é analisar a conversão do uso e ocupação do solo para cana-de-açúcar na microrregião sudoeste de Goiás, no período 2001-2006 e no ano de 2011, por meio de imagens obtidas por satélites de sensoriamento remoto, tratadas e interpretadas com auxílio de técnicas de geoprocessamento. Especificamente, pretende-se verificar se a expansão canavieira na referida microrregião está ocupando ou não áreas de agricultura em detrimento das pastagens, corroborando ou não com a hipótese estabelecida pela Unicamp/Unica (2005), pelo ZAE-Cana (2009) e pelo Plano Nacional de Agroenergia (PNAE, 2006) de que o cultivo da cana-de-açúcar está se estabelecendo prioritariamente em áreas de pastagens ditas degradadas.

\section{Metodologia}

A microrregião sudoeste do estado de Goiás (Figura 1) está localizada entre os paralelos $16^{\circ} 27^{\prime}$ e $19^{\circ} 15^{\prime} \mathrm{S}$ e os meridianos $53^{\circ} 12^{\prime}$ e $50^{\circ} 12^{\prime} \mathrm{W}$, sendo composta pelos municípios de Aparecida do Rio Doce, Aporé, Caiapônia, Chapadão do Céu, Castelândia, Doverlândia, Jataí, Maurilândia, Mineiros, Montividiu, Palestina de Goiás, Perolândia, Portelândia, Rio Verde, Santa Helena de Goiás, Santa Rita do Araguaia, Santo Antônio da Barra e Serranópolis, totalizando $49.264 \mathrm{~km}^{2}$, o que corresponde a $14,5 \%$ da área estadual (IBGE, 2012).

Para a identificação das áreas de cultivo de cana-de-açúcar no sudoeste de Goiás, foram analisadas imagens orbitais do satélite Landsat 5, em composições coloridas RGB dos anos base de 2001, 2006 e 2011, compostas pelas bandas 3, 4 e 5 do sensor TM, cenas órbita/ponto identificadas como 222-72, 222-73, 223-71, 222-72, 222-73, 224-71, 224-72 e 224-73. Os softwares utilizados foram o ERDAS Imagine 8.6 e o ArcGis 9.3. 


\section{Sudoeste de Goiás}

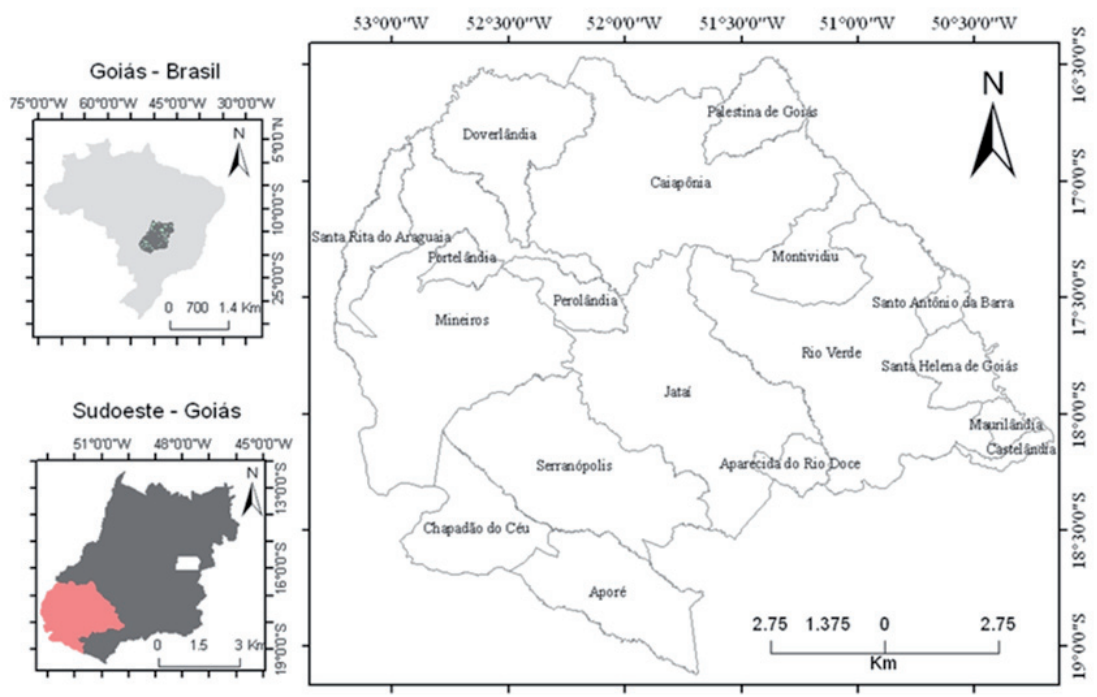

Fonte: SIEG - Sistema Estadual de Estatistica e Informações Geográficas de Goiás, 2010.

Organização: Laboratório de Geoinformação/UFG - Campus Jatai, 2010.

Figura 1 - Localização da microrregião sudoeste no estado de Goiás Fonte: Goiás (2011).

Especificamente, o software ERDAS Imagine 8.6 permitiu que as imagens fossem: 1) agrupadas, gerando a composição colorida 3R 4G 5B; 2) ortorretificadas, utilizando, também, imagens do Landsat 7 de 2002 e cartas topográficas do IBGE na escala 1:100.000 com pontos de controle, sendo reprojetadas para o Geografic Cordinate System, Datum SAD 69, zona $22 \mathrm{Sul}$; 3) classificadas, de forma não supervisionada, onde foram criadas 100 classes, mediante pontos de aferição de campo; 4) agrupadas em pixels com o mesmo valor, obtendo-se oito classes de cobertura do solo.

As áreas de agricultura foram digitalizadas separadamente no software ArcGis 9.3 e, posteriormente, incorporadas à classificação, obtendo-se assim as seguintes classes: a) mata: floresta seca, floresta úmida e cerradão; b) Cerrado: cerrado, campo cerrado; c) campo: campo sujo, campo úmido, campo limpo e campo rupestre; d) corpo d’água: rios, córregos, lagos e lagoas; e) pastagens; f) cana-de-açúcar; g) agricultura: soja, milho, algodão e outros; h) não classificado: sombra de encosta e nuvem. Utilizando o software ERDAS Imagine 8.6, após a classificação, a imagem 
foi filtrada segundo o método do Nearest Neighborhood (vizinho mais próximo, na malha de 3x3 pixels), eliminando-se os pixels com valores isolados e dispersos nas classes determinadas. Na sequência, o arquivo em formato Raster foi transformado em formato Vetorial, sendo então realizados os cálculos das áreas em hectares (ha) e seus perímetros.

A partir da classificação de 2011 foi feita uma sobreposição das áreas de cana-de-açúcar nas imagens de 2001 e 2006, também classificadas, criando-se assim, a obtenção de um padrão espaço-temporal de cobertura e uso das áreas ocupadas pela cana na microrregião.

É importante ressaltar que fatores técnicos - como a ocorrência parcial de nuvens em algumas imagens e a resposta espectral das coberturas do solo em diferentes fases de desenvolvimento da cultura, como plantio, colheita, queima da palha - levaram a uma variação na quantificação das áreas de mapeamento em torno de 5\%.

\section{Resultados e discussão}

O mapeamento da cana-de-açúcar no sudoeste de Goiás revelou que em 2011 a área cultivada era de 263.549 ha, o que representa 6\% da área cultivada com cana no estado no mesmo ano. Esses resultados indicaram que os municípios que apresentaram áreas cultivadas superiores a 5.000 hectares são: Aporé, com 2,3\% da área total da microrregião; Castelândia, 4,3\%; Chapadão do Céu, 13,7\%; Jataí, 5,2\%; Maurilândia, 9,2\%; Mineiros, 19,7\%; Perolândia, 3,2\%; Rio Verde, 6,2\%; Santa Helena de Goiás, 24\%; Santo Antônio da Barra, 3\%; e Serranópolis, 6,7\% (Figura 2).

O Plano Nacional de Agroenergia aponta as pastagens degradadas como as preferenciais para a expansão canavieira. Contudo, nas classificações da cobertura e uso do solo, observou-se que não era possível distinguir as pastagens degradadas das não degradadas, sobretudo por causa da escala adotada. Essa mesma dificuldade foi também detectada por Feltran-Barbieri (2009), que constatou que, para identificar as áreas degradadas, seria necessário testar as nuances espectrais das pastagens reconhecidas nas imagens de satélite com as diferentes fisionomias encontradas em campo, o que demandaria muito tempo e oneraria o custo da pesquisa. Portanto, dadas essas limitações técnicas do método utilizado, não se pode avaliar qual o total de pastos degradados que foi substituído por cana, e, por isso, as duas áreas foram apresentadas em uma única classe, a de pastagem. 


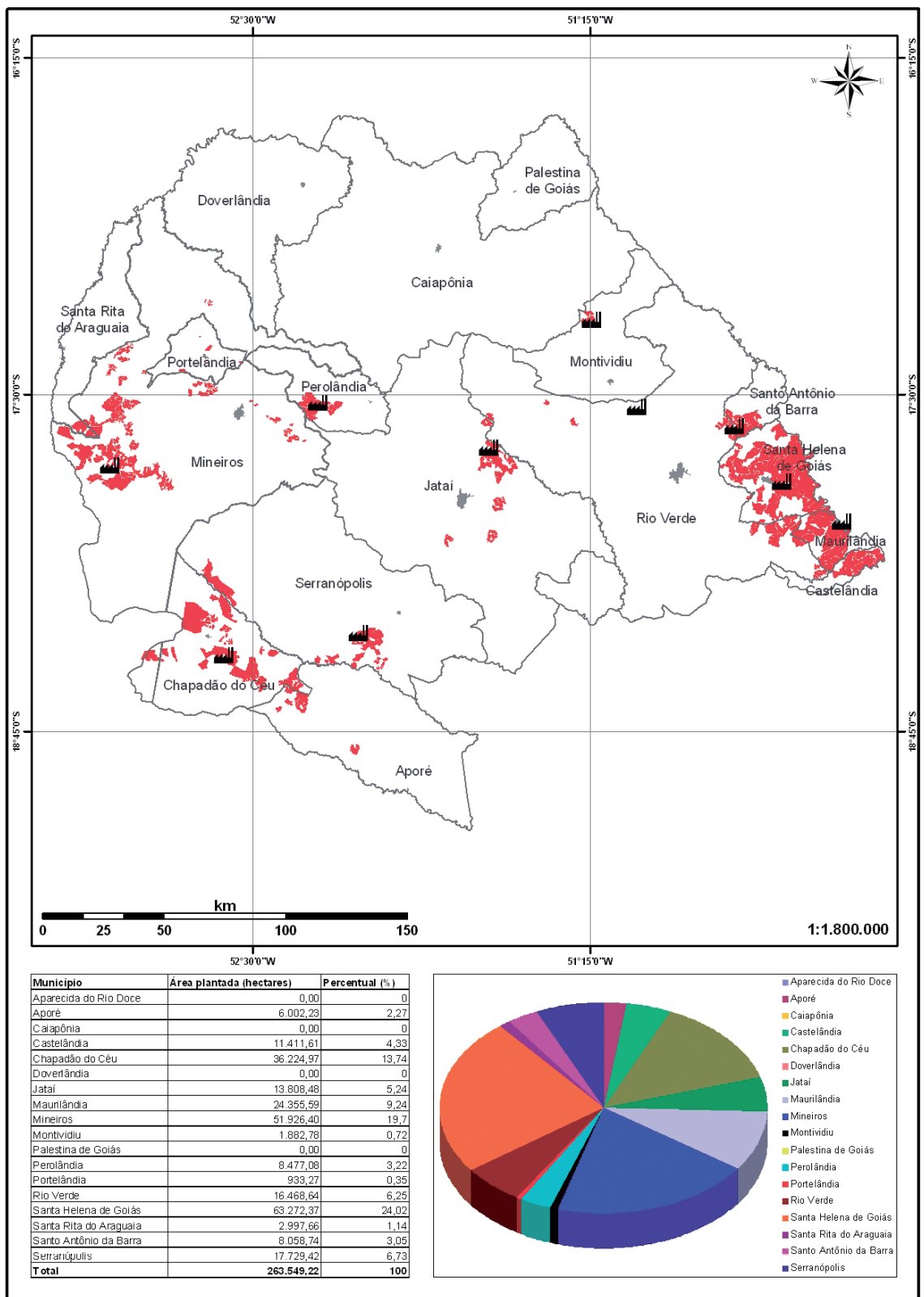

Figura 2 - Área cultivada com cana-de-açúcar no sudoeste de Goiás no ano de 2011 Fonte: Elaborada pela autora, com base em dados do INPE (Brasil, 2011). 
Ribeiro (2010) afirma que, no bioma Cerrado, que compreende os estados de Goiás, Mato Grosso, Mato Grosso do Sul, Minas Gerais e São Paulo, 78\% da área com cana em 2007 coincidia com áreas mapeadas como agricultura em 2002. De fato, $66 \%$ de todo o incremento na área plantada com cana, entre 2005 e 2007, deu-se sobre áreas identificadas como de uso agrícola, sugerindo uma significativa substituição das culturas. Em relação às áreas anteriormente mapeadas como pastagens ou remanescentes de vegetação natural, apenas $20 \%$ e $2 \%$, respectivamente, foram ocupadas com cana em 2007.

Sobre os períodos de 2007-2008 e 2008-2009, Ribeiro (2010) aponta que a maior parte dos incrementos foi mapeada como favorável à expansão da cana. Enquanto isso, as pastagens em geral, nos dois períodos, apresentaram um avanço de 30,3\% e 46,7\%, respectivamente, sugerindo que o avanço da cana ocorreu em pastagens pouco apropriadas, em virtude de os solos serem menos férteis e/ou estarem em áreas de preservação permanente.

Ribeiro (2010) também observou que no estado de Goiás, entre 2005 e 2007, a expansão da cana foi de 37\%. Propondo um cenário em que a expansão ocorra somente em áreas de pastagens e em respeito à legislação ambiental, a cana poderá ocupar $187.682 \mathrm{~km}^{2}$ de cerrado, o que significa 2,5 vezes a área cultivada com cana no estado na safra 2011/2012, que, de acordo com os dados do INPE/CANASAT (Brasil, 2012), era de $73.198 \mathrm{~km}^{2}$. Estimando-se que as terras propícias à expansão, segundo Ribeiro (2010), seja somente áreas de pastagem, o que representa $33,7 \%$, destas, a produtividade natural é baixa em $26 \%$ delas; média, em 50\%; e alta em $24 \%$.

Um estudo realizado por Nassar et al. (2008) mostrou que, dos 103.795 hectares convertidos em cana entre 2007 e 2008, nos estados de Goiás, Mato Grosso e Mato Grosso do Sul, 61\% ocorreram sobre lavouras. Dos cinco estados analisados (Minas Gerais, Goiás, Paraná, Mato Grosso do Sul e Mato Grosso), todos substituíram, majoritariamente, áreas agrícolas entre os anos de 2007 e 2008. Goiás apresenta-se como o segundo estado com a maior porcentagem em áreas agrícolas (70\%) e de pastagens (30\%) no ano de 2007, quando a cana ampliou sua área em 85.560 ha. Já no ano de 2008, Goiás tornou-se, entre esses cinco estados, o de maior porcentagem de substituição em áreas agrícolas (76\%), contra a de pastos (24\%), em uma área cultivada com cana de 143.155 hectares. 
O estudo de Ramos-Neto e Feltran-Barbieri (2009), que incluiu as áreas de cerrado de São Paulo e do oeste baiano, concluiu que, na expansão canavieira ocorrida entre 2004 e 2008, que ampliou o plantio de cana-de-açúcar para 270.735 hectares, 50,4\% ocorreram sobre lavouras, 33\% sobre pastagens, $5,3 \%$ sobre vegetação nativa e 11,2\% em cima de outros usos.

Fazendo uma análise apenas do estado de São Paulo, a área total de agricultura e pastagem substituída pelo plantio da cana até o ano-safra 2008/2009 foi, respectivamente, de 266.272 hectares e 374.180 hectares. Portanto, a expansão do plantio da cana no estado de São Paulo, contrariamente às novas áreas de expansão, ocorreu mais em áreas de pastagens do que nas de uso agrícola (Rudorff et al., 2010).

Em Goiás, segundo Silva e Miziara (2010), é possível identificar duas situações contrastantes entre si, quando se analisa a área num raio de 40 quilômetros das usinas produtoras de etanol. Ao norte, a expansão do cultivo da cana ocorre predominantemente sobre o cerrado e na porção sul, em substituição às áreas agropecuárias. Percebe-se que, em relação às áreas com outras formas de uso que perderam lugar para o cultivo da cana-de-açúcar, a agricultura aparece em primeiro lugar, com 14,4\%, seguida pelo cerrado, com 7,7\%; pelas matas - áreas de não cerrado situadas na porção sul do estado, com 4,8\%; e, por fim, pela pecuária, com $3,7 \%$. Considerando apenas as áreas onde o cultivo da cana foi efetivado, pode-se confirmar que 67\% das culturas praticadas em 2002 foram substituídas. Goiás, portanto, divide-se em duas tendências espaciais de expansão: a do norte e a do sul.

Assim, sabendo-se que a expansão canavieira na região sul de Goiás ocorre em substituição às áreas de agropecuária, tornam-se necessários estudos que visem a auxiliar a elaboração de planos estratégicos de produção de alimentos e de atendimento à demanda global por etanol. Para tanto, e na busca por equilíbrio, o monitoramento é fundamental, e, se realizado via imagens de satélite, é extremamente útil e rápido.

O Plano Nacional de Agroenergia do Ministério da Agricultura, que estimula a expansão do etanol, postula que as metas de produção sejam alcançadas sem colocar em xeque a segurança alimentar, as exportações agrícolas, e sem recorrer ao desmatamento para criar novas áreas de cultivo. Este último ponto é particularmente delicado, em razão do desempenho pífio do Brasil no que diz respeito à proteção das florestas nativas e à questão polêmica da expansão da cultura da soja na Amazônia Legal (Sachs, 2007). Mas é necessário atentar para as condições de produção dos 
biocombustíveis, uma vez que podem se tornar mais impactantes ao meio ambiente do que o próprio combustível fóssil.

Quanto à competição pelos solos agriculturáveis dos biocombustíveis com a produção de alimentos, Sachs (2007) ressalta a importância de sistemas integrados de produção de alimentos e energia adaptados aos diferentes biomas, tais como a integração biodiesel-pecuária e biodiesel-áreas degradadas e a plantação de pinhão-manso em terras degradadas e semidesérticas. Para esses sistemas deverão ser usados, além do custo/ benefício tradicional, tanto critérios ambientais e sociais, em particular a eficiência energética (energy in/energy out), o sequestro de carbono, a produtividade por hectare, a demanda por água, quanto critérios sociais, com especial destaque para a geração de oportunidades de trabalho decente na produção da biomassa, no seu processamento, nos serviços de acompanhamento e de transporte e no aproveitamento dos subprodutos.

Feltran-Barbieri (2009) realizou, no período de meados de 2007 a março de 2009, um estudo sobre cobertura e uso do solo em três municípios do sudoeste de Goiás, Chapadão do Céu, Mineiros e Portelândia, onde observou a substituição de grãos e pastagens em favor da expansão da cana-de-açúcar. Com relação à substituição das áreas de agricultura pela cana-de-açúcar, o pesquisador constatou que em Chapadão do Céu e Portelândia ela foi de $88,2 \%$ e $80,2 \%$, respectivamente, e em Mineiros, de $37,8 \%$. Já a substituição de pastagens por cana foi mais expressiva no município de Mineiros, com 58,9\%, enquanto em Chapadão do Céu e Portelândia foi de 8,8\% e 14,3\%, respectivamente. Entretanto, convém lembrar que o uso do solo predominante nesses municípios é agrícola.

Ainda nesse mesmo estudo, Feltran-Barbieri (2009) comprovou, mediante entrevistas com funcionários das usinas de Alto Taquari, Chapadão do Céu, Mineiros e Portelândia, que 88\% delas estão orientadas para a não prospecção das áreas de pastagens degradadas. Além disso, o autor constatou nos municípios desmatamentos concomitantes com a expansão da cana, os quais superaram todas as médias históricas disponíveis para a região, mesmo considerando os períodos de franca expansão da soja. $\mathrm{E}$ ainda detectou que, quando as áreas de lavouras eram convertidas em cana, os resquícios de vegetação nativa eram absorvidos em quantidades muito menores do que quando contíguos ou inseridos nas pastagens convertidas. Para se ter uma ideia melhor da magnitude do processo, a cada 10 hectares de pasto convertido, foram desmatados 1,12 hectare de cerrado a ele associado (Feltran-Barbieri, 2009). 
Apesar de o estudo de Feltran-Barbieri ter analisado apenas três dos dezoito municípios do sudoeste de Goiás, os resultados que obteve são similares aos levantados para este trabalho, realizado em quatorze municípios do sudoeste de Goiás. Todos eles apresentaram áreas cultivadas com cana-de-açúcar, de acordo com as imagens de satélites do ano de 2011.

Seguem-se dados da análise da cobertura e uso do solo realizada nos municípios de Aporé, Castelândia, Chapadão do Céu, Jataí, Maurilândia, Mineiros, Montividiu, Perolândia, Portelândia, Rio Verde, Santa Helena, Santa Rita do Araguaia, Santo Antonio da Barra e Serranópolis, com os valores das áreas de agricultura, cerrado e pastagem que foram substituídas por cana nas análises temporais de 2001-2006 e 2011 (Figuras 3, 4 e 5).

No município de Aporé, no período de 2001-2006 houve um aumento da área agricultável, 3.202 hectares (ha), em função da diminuição de pastagem, que foi de 3.416 ha, na área que em 2011 foi totalmente subs-

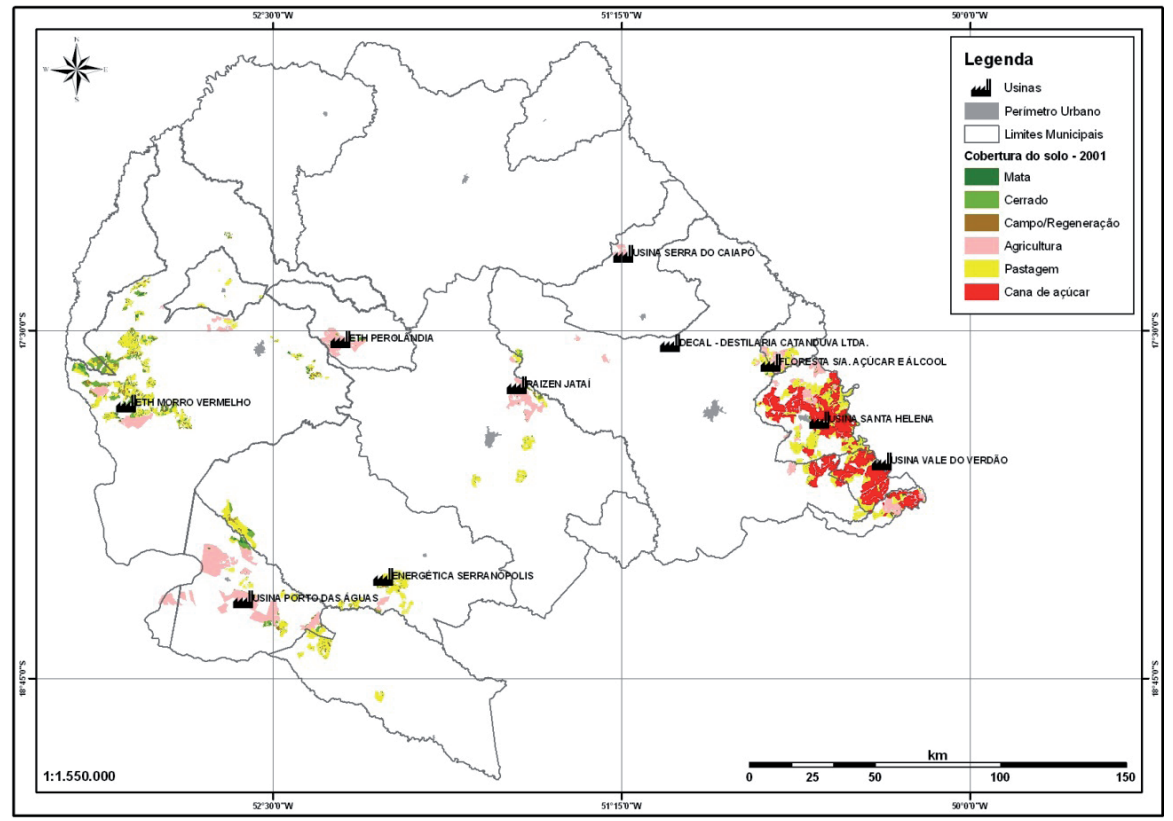

Figura 3 - Cobertura e uso do solo em 2001 nas áreas com cana-de-açúcar em 2011, no sudoeste de Goiás

Fonte: Elaborada pela autora, com base nos dados do INPE (Brasil, 2012) e do SIEG (Goiás, 2006). 
tituída por cana-de-açúcar. De toda área cultivada com cana-de-açúcar no ano de 2011, num total de 6.002 ha, 53,6\%, 30,6\% e 15,6\% ocorreram em áreas onde, em 2006, dominavam agricultura, pastagem e cerrado, respectivamente. Nesse município, no ano de 2011, segundo dados do IBGE (2014), a área de cana era de 4.755 ha, enquanto a área de soja representava $52 \%$ dessa área.

No município de Castelândia, no período de 2001-2006 houve uma diminuição de áreas de agricultura, cerrado e pastagem, em favor da expansão da cana. As áreas de agricultura diminuíram 3.657 ha; a de pastagem, 2.127 ha; e a de cerrado, 652 ha, o que representa 32,1\%, 18,6\% e $6,6 \%$ das áreas de agricultura, pastagem e cerrado, respectivamente, que foram substituídas por cana no ano de 2011. Como o município apresenta um histórico de produção de cana, se comparado a outros do sudoeste de Goiás, no ano de 2001, a área cultivada com esse cultivar já representava $43,6 \%$ dos 4.981 ha ocupados por ele no ano de 2011. De 2001 a 2006

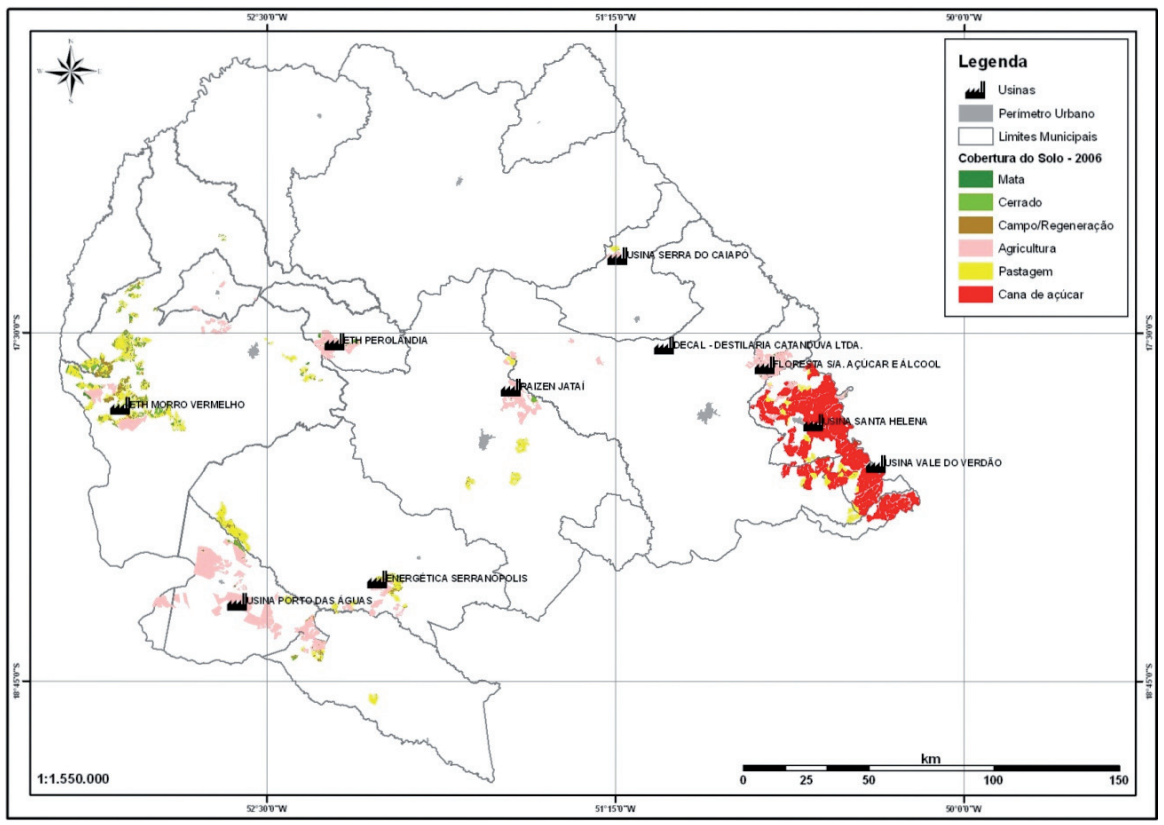

Figura 4 - Cobertura e uso do solo em 2006 nas áreas com cana-de-açúcar em 2011, no sudoeste de Goiás

Fonte: Elaborada pela autora, com base em dados do INPE (Brasil, 2012) e do SIEG (Goiás, 2006). 
houve um aumento de área cultivada com cana, que passou de 6.269 ha para 11.296 ha, ou seja, com um crescimento de 55,5\%.

No município de Chapadão do Céu, no período de 2001-2006 houve um aumento da área agricultável, que atingiu 6.010 ha, em função da diminuição da área de pastagem em 3.495 ha, e a de cerrado, em 2.182 ha. Em 2011, 94,8\% da área plantada com cana-de-açúcar no município era anteriormente reservada à agricultura; 2,4\%, à pastagem; e 2,3\% era de cerrado. Comparando-se esses dados com os resultados obtidos por Feltran-Barbieri (2009), a área de agricultura substituída por cana teve um acréscimo de 6,6\% de 2009 a 2011, enquanto na de pastagem houve uma diminuição de $6,5 \%$. Portanto, os valores obtidos nos dois estudos indicam que a cana avançou preferencialmente sobre áreas de agricultura.

No município de Jataí, no período de 2001-2006 houve um pequeno aumento da área de agricultura, da ordem de 857 ha, em função da diminuição de 419 ha de pastagens e de 440 ha de cerrado. Mas essa área, além de 12.951 ha, foi totalmente substituída pela cana-de-açúcar em

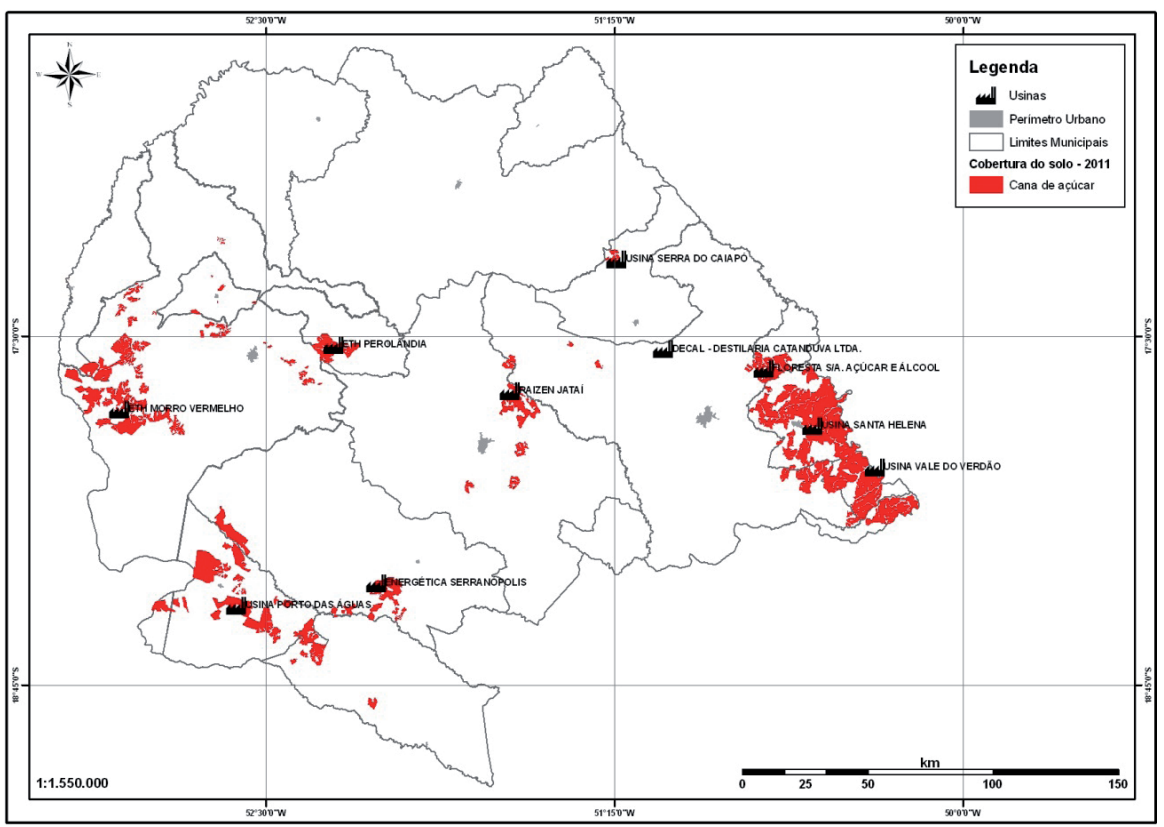

Figura 5 - Áreas cultivadas com cana-de-açúcar no sudoeste de Goiás no ano de 2011 Fonte: Elaborada pela autora, com base em dados do INPE (Brasil, 2012) e do SIEG (Goiás, 2006). 
2011. Até 2006, 65,4\% das áreas agricultáveis do município eram ocupadas pela agricultura; 30\%, com pastagens; e 4,5\% eram cerrado. Segundo dados do IBGE (2012), de 2006 a 2010 somente a área cultivada com soja retraiu 20.000 ha, o que sugere sua substituição, em boa parte, pela cana-de-açúcar.

No município de Maurilândia, no período de 2001-2006 houve um aumento de 642 ha da área de cerrado e uma diminuição de 2.088 ha da área de pastagem. Em 2001, no entanto, a cana já ocupava 19.123 ha da área agricultável do município, o que corresponde a 78,4\% da área que viria a ser cultivada com essa planta em 2011. De 2001 a 2006, a participação em área da cana aumentou 11,2\%, e em 2011 já abrangia 24.355 ha, dos quais $9,64 \%$ e $0,74 \%$ eram áreas de pastagem e de cerrado, respectivamente, em 2006.

No município de Mineiros, no período de 2001-2006 houve um aumento de 2.141 ha na área de agricultura e de 217 ha na de cerrado, paralelamente a uma diminuição de 2.231 ha de pastagem, que em 2011 foram substituídas por cana-de-açúcar. De toda área cultivada com cana-de-açúcar no ano de 2011 - 51.926 ha -, 24,6\%, 39,1\% e 36,3\% ocorreram em locais onde, em 2006, eram praticadas a agricultura, a pecuária, e cerrado, respectivamente. Comparando-se esses dados com os de Feltran-Barbieri (2009), a área de agricultura substituída por cana-de-açúcar diminuiu 13,2\% entre 2009 e 2011, aumentando consideravelmente a de conversão da pastagem e, consequentemente, a de cerrado remanescente a ela associada, no total de 75,3\%. Apesar de as áreas agrícolas terem diminuído em áreas substituídas pela cana de 2009 a 2011, isto não foi suficiente para aumentar as áreas cultivadas com grãos no município de Mineiros. Conforme dados do IBGE (2012), de 2006 a 2011 somente a área cultivada com soja retraiu $48 \mathrm{mil} \mathrm{ha.}$

No município de Montividiu, no período de 2001-2006 houve um pequeno aumento da área de agricultura, de 505 ha. Mas em 2011, toda a área cultivada com cana-de-açúcar, 1.882 ha, era de agricultura em 2006. Apesar disso, segundo dados do IBGE (2014), a cana ainda é uma área pouco expressiva, representando apenas $8 \%$ dos 108.000 ha plantados de soja no município.

No município de Perolândia, de toda área cultivada com cana-de-açúcar no ano de 2011, 8.477 ha, 92,3\%, 0,02\% e 7,7\% ocorreram em áreas onde em 2006 eram agricultura, pastagem e cerrado, respectivamente. 
No município de Portelândia, dos 933 ha cultivados com cana-de-açúcar no ano de 2011, 0,29\% eram áreas agricultura; 91,06\%, de pasto; e 8,65\%, de cerrado, em 2006. Esta última informação contradiz os resultados de Feltran-Barbieri (2009) sobre áreas convertidas para cana, o que pode ser atribuído ao fato de o recorte temporal do presente trabalho ter sido maior. Portanto, acredita-se que, entre os anos de 2006 a 2009, esse município tenha transferido suas áreas de pasto para a agricultura, de tal modo que em 2009 mais de 80\% das áreas agrícolas foram convertidas à cultura da cana-de-açúcar.

No município de Rio Verde, no período de 2001-2006 houve um aumento de 1.323 ha na área de agricultura e de 2.262 ha na de cana-de-açúcar, enquanto as áreas de pastagem diminuíram 2.830 ha e as de cerrado, 797 ha. De toda área cultivada com cana-de-açúcar no ano de 2011, 16.468 ha, $26,81 \%, 17,14 \%$ e 1,44\% ocorreram em áreas onde em 2006 eram agricultura, pastagem e cerrado, respectivamente.

No município de Santa Helena, houve uma diminuição de 3.484 ha na área de agricultura; 16.137 ha, de pastagem; e 2.336 ha, de cerrado, no período de 2001 a 2006, em favor da cultura da cana-de-açúcar. Nesse mesmo período, o cultivo da cana-de-açúcar teve um acréscimo de área de 21.877 hectares, passando de 34.477 ha em 2001 para 56.354 ha em 2006. Dos 63.272 ha cultivados com cana-de-açúcar no ano de 2011, 4,96\%, $5,21 \%$ e $0,63 \%$ ocorreram em áreas que em 2006 eram de agricultura, pastagem e cerrado, respectivamente. A pequena percentagem de cobertura e usos substituídos pela cana em 2006 indica que o município de Santa Helena já apresentava uma produção expressiva de cana anterior à dos outros municípios da microrregião, como confirmam a Produção Agrícola Municipal do IBGE entre os anos de 2004 e 2011 (IBGE, 2014).

No município de Santa Rita do Araguaia, houve uma diminuição (175 ha) da área de cerrado e um pequeno aumento (169 ha) na área de pastagem de 2001 a 2006. De toda área cultivada com cana-de-açúcar no ano de 2011 - 2.997 ha -, 36,32\% ocorreram em áreas onde em 2006 dominavam as pastagem e $63,68 \%$ nas de cerrado, o que sugere desmatamento.

No município de Santo Antônio da Barra, no período de 2001-2006 houve uma diminuição das áreas de pastagem e de cerrado, de 2.723 ha e 155 ha, respectivamente, em favor da agricultura, que teve um acréscimo de área de 2.878 ha, passando de 5.072 ha em 2001 para 7.950 ha em 2006. De toda área cultivada com cana-de-açúcar no ano de 2011 - 8.058 ha 
-, 98,81\% ocorreram em áreas onde em 2006 dominavam a agricultura, ainda que apresentassem $0,03 \%$ de pastagem e 1,14\% de cerrado.

No município de Serranópolis, houve uma diminuição de 3.854 ha nas áreas de pastagem e 1.069 ha nas de cerrado, em favor da agricultura, que teve um acréscimo de área de 4.934 ha, passando de 1.235 ha em 2001 para 6.169 ha em 2006. Apesar do aumento da área de agricultura, ela não foi suficiente para representar a maior porcentagem de área substituída por cana. De toda área cultivada com cana-de-açúcar no ano de 2011, totalizando 17.729 ha, 34,79\%, 52,24\% e 12,97\% ocorreram em áreas onde em 2006 dominavam a agricultura, pastagem e cerrado, respectivamente.

Em suma, fazendo uma comparação entre os municípios citados, pode-se constatar a predominância da conversão de áreas agrícolas e secundariamente de pastagens em favor do plantio da cana-de-açúcar. Nesse sentido, a sobreposição do mapa de cobertura de 2006, elaborado com base nas imagens de satélite, ao das áreas cultivadas com cana no ano de 2011 confirma que a expansão não ocorreu preferencialmente sobre as pastagens. De toda a área cultivada com cana-de-açúcar no ano de 2011, correspondente a 263.549 hectares, 55\% ocorreram em áreas onde dominava a agricultura, contra $28 \%$ de pastagem e $17 \%$ de cerrado. Deste modo, a classe agricultura prevalece entre as que foram substituídas pela cana-de-açúcar no ano de 2011, apesar de ter ocorrido também a ocupação das pastagens, mas em índice menor.

Os municípios que apresentaram substituições acima de $50 \%$ em áreas que em 2006 eram usadas para a agricultura foram: Montividiu, 100\%; Santo Antônio da Barra, 99\%; Chapadão do Céu, 95\%; Jataí, 65\%; e Aporé, 54\%. Já Mineiros, Portelândia e Serranópolis tiveram as maiores conversões em áreas de pastagem.

O Zoneamento Agroecológico da Cana-de-Açúcar, o ZAE-Cana (Manzatto 22222, 2009), em consonância com o Plano Nacional de Agroenergia (Brasil, 2006), incentivou a expansão da cana-de-açúcar em áreas de pastagens degradadas, ou seja, em áreas que apresentam solos de baixa fertilidade natural, restrições de declive e/ou o estabelecimento, formação e manejo da pastagem precária, condições essas frequentemente encontradas na pecuária extensiva no estado de Goiás.

Essa preferência por áreas anteriormente cultivadas com agricultura pode ser explicada, em parte, pela fertilidade do solo, mas também pela logística, sobretudo de transportes. Nesse sentido, o manejo da mo- 
nocultura da soja na região, há quase 40 anos, promoveu a correção dos solos, safra a safra, além do revolvimento por arado e grade, favorecendo a porosidade. Também as pastagens manejadas normalmente a cada três anos, com aplicação de calcário e ureia, além de serem reformadas, quando o são, em tempos muito mais longos, sem um padrão reconhecido, fazem com que os solos cultivados com grãos sejam mais atraentes, por causa do menor custo de produção, relacionado à maior fertilidade e menor compactação, quando comparados aos da pastagem. Esse fator aparece quando se comparam os rendimentos médios dos canaviais cultivados em um ciclo de cinco anos, em que o declínio médio em áreas de pastagens chega a ser 64\% superior ao das áreas de agricultura.

Por outro lado, o custo de implantação da cana torna-se maior em áreas de pastagens do que em áreas de agricultura, por causa das quantidades maiores de insumos para a correção do solo, necessárias para uma boa produtividade da cana nas áreas de pasto (Feltran-Barbieri, 2009).

A proximidade dos talhões até a usina é também, conforme Feltran-Barbieri (2009), um fator decisivo para o custo logístico de transporte da matéria-prima para a moagem. Ressalte-se que, para a maioria das usinas instaladas na região do sudoeste de Goiás, um raio de 25 a 50 quilômetros determina o território de cada grupo usineiro, o que pode gerar certa pressão nos preços de arrendamento ou compra de propriedades rurais para o cultivo da cana.

Tal distância até as usinas permite compreender o avanço da cana sobre áreas de agricultura, pois estas são atendidas por uma boa parcela das estradas rurais em boas condições de rodagem, além de apresentarem, em média, menos de 6\% de declive, o que não ocorre em áreas que têm como atividade principal a pecuária. Além disso, o formato essencialmente quadrangular das áreas de soja e as extensas formações tabulares de chapadas permitem que a maioria das vias seja traçada em linha reta, o que as torna mais econômicas para o setor canavieiro, por reduzirem substancialmente os custos do frete da cana, balizado na quilometragem percorrida.

Segundo Camelini e Castillo (2012), os principais critérios de seletividade espacial do setor sucroenergético são: 1) físicos - disponibilidade de terras agricultáveis; adequação dos solos às necessidades da planta; existência de condições clinográficas adequadas; clima e disponibilidade hídrica; 2) econômicos - custo da terra; estrutura para fornecimento de in- 
sumos e serviços; disponibilidade de força de trabalho; 3) infraestruturais e políticos - boa condição logística; disponibilidade de variedades adaptadas; legislação ambiental com poucas restrições; restrições das áreas de plantio; vantagens decorrentes de benefícios fiscais.

Diferentemente de outras culturas - por exemplo, a soja, cujos grãos podem ser armazenados por longos períodos (respeitadas algumas condições técnicas) ou transportados por grandes distâncias até o seu processamento industrial sem perdas consideráveis de propriedades -, a proximidade com o centro de moagem é fundamental no que se refere à cana-de-açúcar. Isso leva ao estabelecimento de quadros agressivos de ocupação, resultando invariavelmente na formação de imensas áreas sob o regime de monocultura e prevalecendo a rigidez locacional da estrutura agrária das regiões.

\section{Conclusão}

O mapeamento revelou que a cana-de-açúcar no sudoeste de Goiás, no ano-safra 2011/2012, ocupava 263.549 hectares, equivalente a $36 \%$ da área com essa cultura no estado. Em 2011, o cultivo da cana-de-açúcar nesta microrregião ocorreu em áreas onde, em 2006, dominavam a agricultura (55\%), a pastagem (28\%) e o cerrado (17\%). Desse modo, as áreas de agricultura representam mais da metade de todas as áreas substituídas por cana-de-açúcar no ano de 2011, comprovando a disputa por terras entre o setor carne-grãos e a inequívoca preferência por áreas de agricultura, dadas as vantagens agronômicas e logísticas, quando comparadas às áreas de pastagem.

\section{Agradecimentos}

Agradecimento especial ao Programa de Pós-graduação em Geografia da Universidade Federal de Goiás, Campus Jataí, e à Coordenação de Aperfeiçoamento de Pessoal de Nível Superior (CAPES) pelo apoio financeiro para a realização da pesquisa de mestrado, com vigência de março de 2010 a março de 2012.

\section{Referências}

BRASIL. Ministério da Agricultura, Pecuária e Abastecimento. Plano Nacional de Agroenergia 2006-2010. Brasília, 2006. 
- Ministério de Ciência, Tecnologia e Inovação. Instituto Nacional de Pesquisas Espaciais (INPE/CANASAT). Mapeamento da Cana via Imagens de Satélite de Observação da Terra. São José dos Campos, 2012. Disponível em: < http://www.dsr.inpe.br/canasat >. Acesso em: jun. 2011; mar. 2012.

CAMELINI. J. H.; CASTILLO, R. Etanol e uso corporativo do território. Mercator, Fortaleza, v. 11, n. 25, p. 7-18, maio/ago. 2012.

FELTRAN-BARBIERI, R. Biocombustíveis, controvérsia agrícola na economia do petróleo: o caso do etanol no Cerrado. Tese (Doutorado em Ciência Ambiental). Programa de Pós-graduação em Ciência Ambiental da Universidade de São Paulo. São Paulo, 2009.

GOIÁS. Sistema Estadual de Estatística e de Informações Geográficas de Goiás (SIEG). Cobertura e Uso do Solo do Estado de Goiás do ano de 2006. Goiânia, 2006. Disponível em: <http://www.sieg.go.gov.br>. Acesso em: out. 2010.

IBGE. Instituto Brasileiro de Geografia e Estatística (IBGE). Sistema IBGE de Recuperação Automática (SIDRA). Produção Agrícola Municipal (PAM). Rio de Janeiro: IBGE, 2006 Disponível em: <http://www.sidra.ibge.gov.br/bda/acervo/ acervo2.asp? $=\mathrm{v} \& \mathrm{p}=\mathrm{PA} \& \mathrm{z}=\mathrm{t} \& \mathrm{o}=11>$. Acesso em: mar. 2012/jun. 2014.

MANZATTO, C. V.; ASSAD, E. D.; BACCA, J. F. M.; ZARONI, M. J.; PEREIRA, S. E. M. (Orgs.). Zoneamento agroecológico da cana-de-açúcar. Ministério da Agricultura Pecuária e Abastecimento (MAPA). Empresa Brasileira de Pesquisa Agropecuária (EMBRAPA SOLOS). Rio de Janeiro: Embrapa Solos, 2009. Disponível em: <http://www.planalto.gov.br/ccivil_03/_Ato2007-2010/2009/ Decreto/D6961.htm>. Acesso em: fev. 2010.

NASSAR, A. M.; RUDORFF, L. B. A.; AGUIAR, D. A.; BACCHI, M. R. P.; ADAMI, M. Prospects of the sugarcane expansion in Brazil: impacts on direct and indirect land use changes. In: ZUURBIER, P.; VOOREN, J. V. (Eds.). Sugarcane ethanol: contributions to climate change mitigation and the environment. 1rst ed. Wageninguen: Wageniguen Publs, 2008. p. 63-94.

RAMOS-NETO, M. B.; FELTRAN-BARBIERI, R. The truth about brazilian sugarcane etanol. Revista Biomass \& Bioenergy, jun. 2009.

RIBEIRO, N. V. Expansão sucroalcooleira no Bioma Cerrado: tendências, cenários e impactos. Tese (Doutorado em Geografia). Programa de Pós-graduação em Geografia da Universidade Federal de Goiás, Goiânia, 2010.

RUDORFF, B. F. T.; BERKA, L. M. S.; XAVIER, A. C.; MOREIRA, M. A.; DUARTE, V.; ROSA, V. G. C.; SHIMABUKURO, Y. E. Estimativa de área plantada com canade-açúcar em municípios do estado de São Paulo por meio de imagens de satélites e técnicas de geoprocessamento: ano safra 2003/2004. São José dos Campos, SP: Instituto Nacional de Pesquisas Espaciais, 2004. (INPE-10791-RPQ/759)

_-_____ _ _______ ___________________________ ;______. Imagens de satélite no mapeamento e estimativa de área de cana-de-açúcar em São Paulo: ano safra 2003/2004. Agricultura em São Paulo, v. 52, n. 1, p. 21-29, 2005.

; AGUIAR, D. A.; SILVA, W. F.; SUGAWARA, L. M.; ADAMI, M.; MOREIRA,

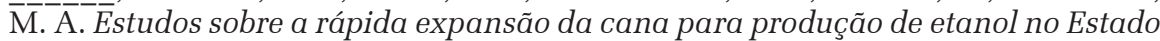
de São Paulo (Brasil) utilizando dados do Landsat. Instituto Nacional de Pesquisas 
Espaciais (INPE), Divisão de Sensoriamento Remoto (DSR). São José dos Campos, SP, 2010.

SACHS, I. A revolução energética do século XXI. Estudos Avançados, v. 21, n. 59, p. 21-38, 2007.

SILVA, A. A.; MIZIARA, F. A expansão da fronteira agrícola e a localização das usinas de cana-de-açúcar. Revista Sociedade \& Natureza, mar. 2010.

UNICA. União da Indústria de Cana-de-açúcar. Universidade Estadual de Campinas. Núcleo Interdisciplinar de Planejamento Energético. Fundação de Desenvolvimento da Unicamp. Convênio: CGEE - Centro de Gestão e Estudos Estratégicos. Relatório: Estudo sobre as possibilidades e impactos da produção de grandes quantidades de etanol visando à substituição parcial de gasolina no mundo. dez. 2005.

Íria Oliveira Franco - Possui Graduação em Ciências Biológicas pela Universidade Federal de Goiás. Possui Mestrado em Geografia e Especialização em Meio Ambiente: Educação e Gestão Ambiental pela mesma Universidade. Atualmente é consultora ambiental e funcionária na empresa Raízen. 